\title{
The Female (and Male) Athlete Triad: Updates, Nutrition Implications, and Screening Tools to Prevent Low Bone Mineral Density
}

Kim Schwabenbauer

Department of Human Services, Rehabilitation, Health and Sport Sciences, Clarion University, 229 Ralston Hall, 840 Wood Street, Clarion, PA 16214, United States.

\author{
Article Details \\ Article Type: Research Article \\ Received date: $29^{\text {th }}$ August, 2020 \\ Accepted date: $15^{\text {th }}$ October, 2020 \\ Published date: $19^{\text {th }}$ October, 2020
}

"Corresponding Author: Kim Schwabenbauer, Department of Human Services, Rehabilitation, Health and Sport Sciences, Clarion University, 229 Ralston Hall, 840 Wood Street, United States. E-mail: kschwabenbauer@clarion.edu

Citation: Schwabenbauer, K. (2020). The Female (and Male) Athlete Triad: Updates, Nutrition Implications, and Screening Tools to Prevent Low Bone Mineral Density. J Rehab Pract Res 1(1):113. https://doi.org/10.33790/jrpr1100113

Copyright: (C2020, This is an open-access article distributed under the terms of the Creative Commons Attribution License 4.0, which permits unrestricted use, distribution, and reproduction in any medium, provided the original author and source are credited.

\section{Abstracts}

Numerous physiological and psychological benefits are afforded to those who participate in regular physical activity, including long-term protection against diseases such as obesity, cardiovascular disease, and diabetes, as well as improved bone health and a reduction in anxiety. However, medical issues can arise in both active males and females if proper care is not taken to match energy intake to energy expenditure. Knowledge of how to assess active individuals for the presence of one or more of the triad components is critical for male and female physicians, coaches, and athletic trainers. This review article will examine the complex dose-response relationship between reductions in energy availability and the disruption of hormonal responses that negatively impact bone mineral density in exercising males and females. In addition, critical strategies for the prevention, accurate identification, and treatment of the Triad will be discussed.

Keywords: Female an Male Athlete Triad, Female Athlete Triad, Amenorrhea, Bone Mineral Density, Low Energy Availability, Athletes, Physical Activity

\section{Definition}

High school and collegiate athletics provide a fantastic venue for both genders to learn and grow as individuals. Numerous physiological, psychological, educational, and social benefits are afforded to those who participate in athletics, including a more favorable self-image, lower anxiety-depression scores, and a personality type that may be more resistant to drug and alcohol addiction [1].

However, medical issues can arise in athletes if proper care is not taken to match energy intake to energy expenditure. It is well established that without adequate energy intake, a range of body functions involved in both health and performance can affect overall health. Due to the recognition of the association between disordered eating, amenorrhea, and musculoskeletal injuries among female athletes, the Task Force on Women's Issues of the American College of Sports Medicine (ACSM) coined the term female athlete triad in 1992. Otis et al. [2] defined the Female Athlete Triad in The ACSM 1997 position stand (and subsequently updated its definition in 2007). Most recently, the Female Athlete Triad Coalition Consensus Statement on Treatment and Return to Play of the Female Athlete Triad expert panel produced a consensus statement that aims to provide clinical guidelines for physicians, athletic trainers and other healthcare providers for the screening, diagnosis, and treatment of the Triad [3]. Due to the realization that males also may exhibit physiological issues related to endocrine, growth, and reproductive health, the female athlete triad was renamed to the female and male athlete triad (the Triad) in 2018.

Previously, underreporting and subsequent lack of prompt treatment has resulted from lack of education among health care professionals, coaches, athletic trainers and athletes, improper screening tools and lack of reporting by athletes to coaches and parents $[2,4,5]$. In addition, due to the updated 2007 definition, an athlete need not present with all three components of the Triad to qualify for a diagnosis. Instead, an athlete needs only present with varying degrees of only one or two of the components and can still meet the criteria for the Triad diagnosis [6]. Therefore, medical professionals, coaches, parents, teammates, and other members of a multidisciplinary team must be made aware of the intricacies of this condition for proper prevention, diagnosis, and treatment of symptoms of the Triad. The purpose of this review is to identify physiological consequences of the Triad and review appropriate screening, identification, and education techniques to assist in the prevention and treatment of the syndrome as well as examine the definition of the Triad, current research in energy availability (EA), reproductive health, and impaired bone health. In addition, management and treatment guidelines and prevention strategies will also be reviewed.

\section{Energy Availability}

According to the 2007 ACSM position stand, the Triad is composed of three interrelated spectrums of low EA (with or without an eating disorder), functional hypothalamic amenorrhea (FHA), and low bone mineral density (BMD) [6]. Clinically, energy availability is defined as "dietary energy intake minus exercise energy expenditure," which is a positive balance that allows for excess energy for bodily functions after exercise when adjusted for kilograms of fat-free mass (FFM) [6]. When an athlete lacks proper energy availability, physiological mechanisms suppress reproductive function, among other bodily processes such as cellular maintenance, growth, and thermoregulation [6]. During times of limited fuel availability, energy is used to maintain vital processes and shifted away from growth and reproduction, while metabolic conservation becomes a priority [7]. Just a few of these metabolic alternations include a decrease in 
resting metabolic rate, triiodothyronine (TT3), leptin, insulin, insulin-like growth factor-1 (IGF-1), and the upregulation of stressrelated hormones such as cortisol [3, 7]. The reasons for an athlete failing to meet energy expenditure requirements can include an underlying eating disorder, intentional dietary restriction to reduce body weight or improve body composition or unintentional failure to adjust energy intake either due to lack of knowledge of requirements or exercise-induced appetite suppression [6].

An extensive body of literature describes athletes participating in aesthetic sports, endurance sports, and sports with weight-class requirements as being particularly susceptible to prolonged periods of low energy availability [8]. Dieting can be a natural first step for athletes looking to control body weight due to performance or aesthetic reasons. However, surveys of exercising women support more negative attitude scores in sports or competitions favoring leanness [6]. In addition, Logue et al. [9] described how both male and female high-performance athletes of all types are susceptible to low energy availability ranging from not consuming enough food to meet energy requirements to disordered eating or eating disorders.

EA was a concept first studied in women in which an EA value of 45 $\mathrm{kcal} / \mathrm{kg} \mathrm{FFM/day} \mathrm{was} \mathrm{suggested} \mathrm{as} \mathrm{positively} \mathrm{associated} \mathrm{with} \mathrm{energy}$ balance and optimal health [10]. In contrast, a sustained reduction in EA, specifically when EA falls below $30 \mathrm{kcal} / \mathrm{kg} \mathrm{FFM/day,} \mathrm{could} \mathrm{be}$ associated with impairment of physiological functioning, including a disruption in the female hypothalamus-pituitary-adrenal (HPA) axis [11]. Even within short-term clinical studies of less than five days, EA values below $30 \mathrm{kcal} / \mathrm{kg}$ FFM/day has been shown to cause negative metabolic and endocrine changes $[12,13]$. However, these studies did not address how this relates to follicular development, ovulation, or luteal function $[13,14]$. However, more recent research does not support an absolute energy availability threshold of $30 \mathrm{kcal} / \mathrm{kg} \mathrm{FFM} /$ day.More recent research highlighted the previously unchallenged notion that women with an energy intake above the established 30 $\mathrm{kcal} / \mathrm{kg}$ FFM threshold should not experience menstrual disturbances $[14,15]$. Therefore, caution should be used when considering a value of $30 \mathrm{kcal} / \mathrm{kg}$ FFM, a guideline for assuming EA is adequate to support normal reproductive function, including luteinizing hormone pulsatility, among females. In men, a value of $40 \mathrm{kcal} / \mathrm{kg} \mathrm{FFM} /$ day has been suggested by current literature to ensure optimal energy availability to sustain proper physiological function [16].

Despite the understanding that low EA has a profound acute and long-term impact on female health among both active males and females, the prevalence is often challenging to determine due to the hazards of measuring EA in free-living athletes $[17,18]$. Options for assessing energy intake include dietary records varying in length, usually 3-7 days, and/or a 24 h dietary recall [19]. However, energy intake can be significantly overestimated or underestimated via selfreported dietary logs and may not represent a long-term picture of energy intake [20]. Chronic markers of energy availability that can be monitored include body weight and body composition, resting metabolic rate and self-reported eating inventories such as the Low Energy in Athletic Females Questionnaire (LEAF-Q), Drive for Thinness (DT) subscale portion of the Eating Disorder Inventory (EDI) and Cognitive Dietary (CDR) Restraint subscale portion of the Three-Factor Eating Questionnaire [7]. While these tools have been most commonly studied in females in relation to eating behaviors, these same screening tools need to be related to disordered eating and energy deficiency in men [7].

\section{Reproductive Dysfunction}

Males and females can experience reduced sex hormones and associated reduced fertility from a lack of adequate energy to support activity. Within females, the spectrum of menstrual function within the definition of the Triad spans from eumenorrhea (normal menstruation status) to amenorrhea (abnormal menstruation status). Eumenorrhea is defined as a "menstrual cycle lasting within one standard deviation of the mean length of 28 days +7 days".
Amenorrhea is defined as the "absence of menstrual cycles lasting more than three month" [6]. After initial menarche, if amenorrhea occurs, it is referred to as secondary amenorrhea [6]. A delay in menarche past 16 years of age, while still exhibiting secondary sexual characteristics, is considered primary amenorrhea [6]. However, primary amenorrhea can be diagnosed as young as 14 years of age if secondary sexual characteristics nor menarche has occurred [6]. Finally, oligomenorrhea is characterized by menstrual cycles occurring at intervals longer than 35 days, but without perceptible symptoms [6]. Within oligomenorrhea, hormonal disturbances can occur at a sub-clinical level [15].

Regardless of age, irregularities within the menstrual cycle are common in women. The disruption of the Hypothalamic-PituitaryOvarian (HPO) axis is caused by a changes in the gonadotropinreleasing hormone $(\mathrm{GnRH})$ secretion from the hypothalamus which signals the release of luteinizing hormone (LH) and folliclestimulating hormone (FSH) from the anterior pituitary [15]. If the LH pulse is delayed, consequences can range from a delay in folliculogenesis or luteal phase shortening to anovulation and complete menstrual suppression [15]. A decreased production of oestrogen can result from this dysfunction of the HPO axis. A hypoestrogenic state can be one of the causes of acute and long-term decreases in BMD [20].

While reproductive hormones are extremely susceptible to changes in energic status in women, research suggests males can withstand a substantial energy deficit before similar metabolic and sex hormones fluctuations, such as testosterone, are induced [21]. Within the short term (i.e., five days) of energy availability manipulation to a value of $15 \mathrm{kcal} / \mathrm{kg} \mathrm{FFM} /$ day in men did not produce the same negative impact on bone formation markers as in females [22]. In a similar study, six exercising men underwent two conditions of low energy availability. However, they did not sustain significant changes in metabolic and sex hormones such as ghrelin, triiodothyronine, testosterone, and IGF-1 [16]. However, intensity and duration may be modulating factors when addressing more significant reductions in metabolic or stress-related hormonal profiles in men. One such study examined those engaged in 8 weeks of army ranger training where energic status was reduced to produce a reduction in total body mass, fat mass, FFM with hormonal changes such as a decline in TT3, IGF1 , and insulin [23]. In other cases, males competing in single bouts of prolonged, strenuous exertion such as "Ultra" running and cycling events of approximately $160-1200 \mathrm{~km}$ in length produced suppression of testosterone, IGF-1 and leptin immediately and following a 12hour recovery period of endurance exercise [24, 25]. Compared to untrained men, those that are considered highly trained do have a reduction in testosterone levels, yet still may fall into normal physiologic ranges [26]. The difficulty of assessment in males lies in the lack of an overt clinical presentations such as those females, (i.e., menstrual changes) and instead require biochemical reproductive and endocrine testing and self-reported changes in libido to trigger additional investigation [27]. Further research with higher-levels of evidence and larger sample sizes are warranted to better quantify the impact of low energy availability on the hypothalamic-pituitarygonadal (HPG) axis in men.

\section{Impaired Skeletal Health}

Within the 2007 ACSM position stand, the "spectrum of BMD ranges from optimal bone health to osteoporosis" [6]. The density, internal structure, and quality of bone protein are vital determinants in fracture risk [6]. Accumulating sub-optimal BMD during the critical period from childhood to adolescence can help determine the risk of osteoporosis and musculoskeletal injury later in life [28]. As part of the 2007 ASCM position stand, BMD should be identified with a Z-score that can be compared to similar age and sex-specific distributions of BMD [6]. Osteoporosis is then defined as having a "BMD two or more standard deviations below the mean of the comparison group, along with other secondary clinical risk factors for bone fracture such as a history of nutritional deficiencies, hypoestrogenism or stress fractures with 
a BMD Z-score between -1.0 and -2.0" [6]. The Z-score is determined from Duel-Energy X-ray Absorptiometry (DXA), a more scientifically accepted method for identifying accurate, reliable, and validated values for bone mineral density.

A substantial amount of evidence supports the integral role of physical activity and, specifically, weight-bearing exercise, to positively influence the development of bone mineral density during this critical period of bone mass accumulation. However, as reproductive hormonal abnormalities, including sub-clinical hormonal changes, accumulate in active individuals, accelerated bone loss and increased risk of fracture can occur [29]. Among females, this is primarily due to hypoestrogenism, which is exhibited in amenorrhoeic and oligomenorrheic females, which does not allow proper accumulation of bone mass [6]. Estrogen is a critical contributor to bone mass through its ability to increase intestinal calcium absorption and suppress bone resorption [29]. Therefore, menstrual irregularities and low BMD concurrently increase stress fracture risk and low BMD Z-scores [6].

In males, previous studies reported low bone mass or osteoporosis among male athletes in leanness sports that favor low body weight or those sports exerting low-impact loading forces [21]. One such hypothesis proposed non-bone loading sports, such as male jockeys, might exhibit low energy availability due to weight-restriction behaviors and exhibit lower BMD compared with age, gender, and BMI matched boxercontrols [30]. Results suggested this was the case, with male jockeys displaying lower total BMD, total body bone mineral content, and less L2-L4 and femoral neck BMD and bone mineral content $(p<0.05)$ [30]. Both boxing and horseback riding have weight-related performance measures. However, the type of loading exerted on the bone during exercise is vastly different. Activities such as boxing that involve high-impact and multidirectional loading lead to increased bone mineralization while those that involve less weight bearing activity, such as horseback riding, do not [31].

Specifically, the belief that being thinner is critical to performance and subsequent energy and nutritional deficits may place male runners at risk for impaired skeletal health[32]. Male endurance sports and sports emphasizing leanness (including runners, cyclists, and jockeys) have, on average, lower BMD than males in nonleanness sports or those that involve high impact and multidirectional bone loading such as soccer, tennis, football, etc. [22]. Therefore, the type of activity and how weight or body composition relates to performance, must be considered when discussing BMD. Few studies in males have demonstrated the effects of low EA on BMD, bone quality, and bone metabolism. In addition, the studies that do exist to date are less definitive in males than in active females and female athletes.

\section{Screening}

One of the most challenging aspects of the Triad is performing an accurate diagnosis. A screening procedure should be completed during preparticipation physical examinations (PPE) and annual physician checkups. If an active male or female presents with a related condition, such as stress fracture or amenorrhea, it is essential to screen for the other criteria $[6,7]$.

Essential components of the initial screening include a detailed, guided history, including questions regarding physical activity, past injuries, diet and eating behaviors, and for females, a menstrual history [33]. Despite the understanding that low energy availability has a profound acute and long-term impact on male and female health among exercising females, it is often challenging to determine due to the hazards of measuring energy availability in free-living athletes [17].

A focused questionnaire, such as the 25-item LEAF-Q, can help attempt to quantify eating habits and exercise energy expenditure [34]. This questionnaire produced $78 \%$ sensitivity and $90 \%$ specificity when tested in 84 female athletes from 18-39. The Female and Male Athlete Triad Coalition recommends the addition of twelve specific questions that are sensitive for identifying the athlete at risk who requires further investigation [35].

\section{Box 1 \\ Triad Consensus Panel Screening Questions*}

- Have you ever had a menstrual period?

- How old were you when you had your first menstrual period?

- When was your most recent menstrual period?

- How many periods have you had in the past 12 months?

- Are you presently taking any female hormones (oestrogen, progesterone, birth control pills)?

- Do you worry about your weight?

- Are you trying to, or has anyone recommended that you gain or lose weight?

- Are you on a special diet, or do you avoid certain types of foods or food groups?

- Have you ever had an eating disorder?

- Have you ever had a stress fracture?

- Have you ever been told you have low bone density (osteopenia or osteoporosis)?

*The Triad Consensus Panel recommends asking these screening questions at the time of the sports preparticipation evaluation.

Positive responses to the questions should trigger additional screening by a physician and other members of the multidisciplinary team. In addition, the Female and Male Athlete Triad Coalition has developed an evidence-based assessment tool to aid physicians and other members of the multidisciplinary team to guide athlete eligibility decisions.

\section{Treatment}

The first and most important treatment goal is to increase energy availability by adjusting energy intake to exceed energy expenditure [6]. However, this can be challenging based on the restrictive eating behaviors developed by athletes and the fear of gaining weight or body fat. While a higher body weight may result from restoring positive energy availability, it doesn't have to preclude restoration of normal menstrual function. A randomized controlled trial in 17 women with functional hypothalamic amenorrhea (FHA) that hat those in the intervention grouptreated with 20 -weeks of cognitivebehavioral therapy restored ovarian activity resolved issues with the limbic-hypothalamic-pituitary-adrenal (LPHA) axis, and initiated partial recovery of the thyroidal access in women with FHA without weight gain [35]. Authors suggested that without addressing attitudes and behaviors that may mitigate hormonal restoration, stress and its accompanying biomarkers, such as free circulating cortisol, are likely to persist.These aspectsmay play a role in both the development and recovery/treatment of FHA.

Qualitative research includes studies that can shed light on thoughts, feelings, and behaviors associated with the cognitive drive for thinness that often accompanies anti-gravitational sports such as long distance running [38]. Two stories told by two endurance runners with diagnosed eating disorders involved weight-loss behaviors, such as food deprivation or excessive exercise, as essential and necessary to their success as athletes [36]. They commented that these narratives and eating behaviors are often linked to selfidentity and framed by cultural discourses, and therefore, need to be explored by trained professionals for evaluation and treatment [36]. Cognitive-behavioral therapy is also suggested to normalize eating 


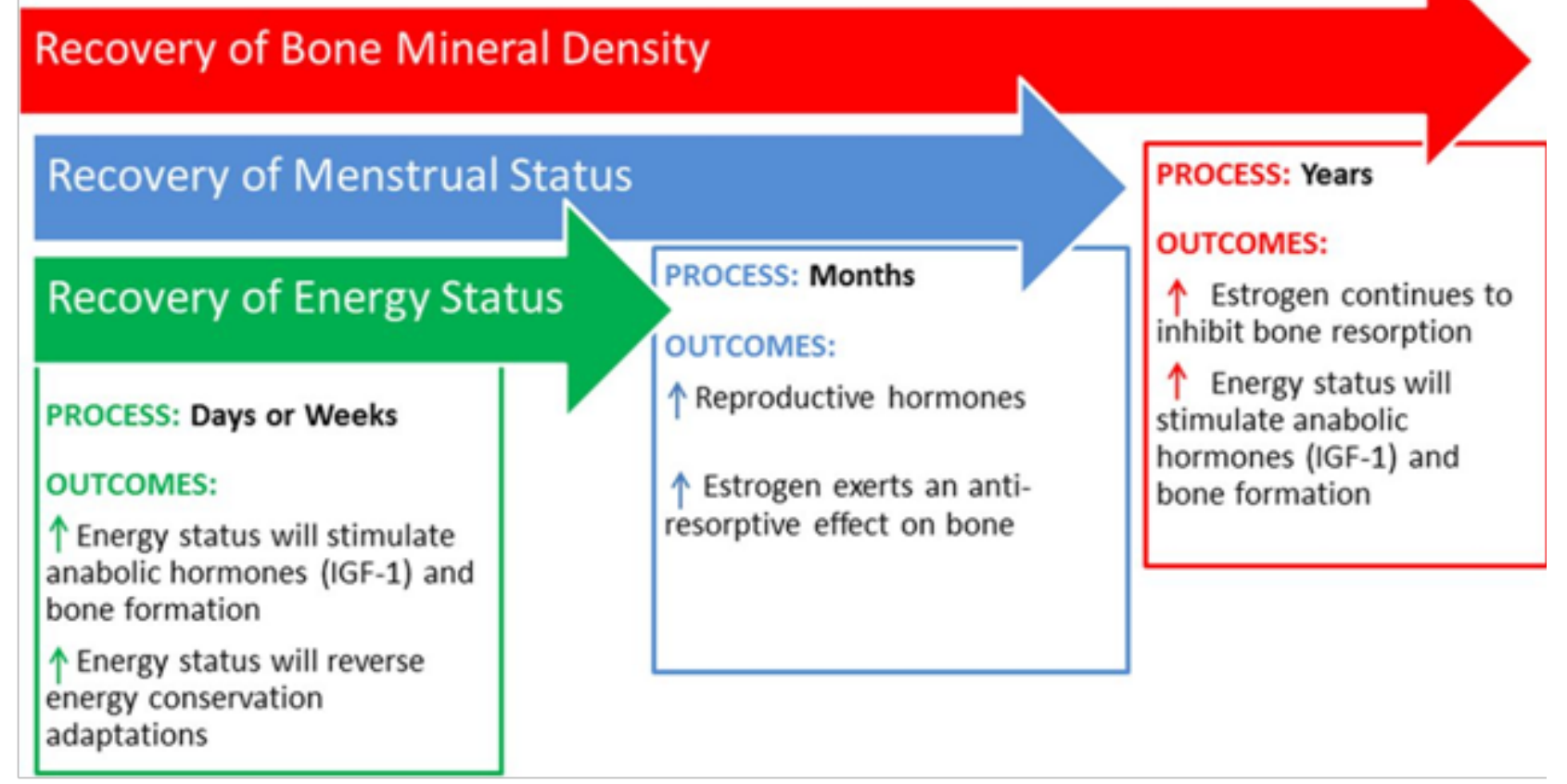

Figure 1. Treatment of the Female Athlete Triad

Note. "The three components of the Triad recover at different rates with the appropriate treatment. Recovery of energy status is typically observed after days or weeks of increased energy intake and/or decreased energy expenditure. Recovery of menstrual status is typically observed after months of increased energy intake and/or decreased energy expenditure, which improves energy status. Recovery of BMD may not be observed until years after recovery of energy status, and menstrual status has been achieved. IGF-1, insulin-like growth factor-1" [7].

behavior and modify unhealthy thought processes while treating emotional issues that initiated dietary restraint practices [6].

\section{Prevention Strategies and Future Directions}

One of the most important strategies to address both the Triad's prevention and treatment is maintaining adequate calories to support vital bodily functions and activity [39]. Pre-season screening and primary prevention strategies can play a vital role in the prevention of the Triad. Nutritional therapy is essential as the first line of treatment for those who have been identified as energy-deficient [37]. Returning the HPA-axis hormones to normal levels while diminishing bone resorption should be the multidisciplinary team's goal addressing the individual's energy deficit. This team should include a physician for assessment and management, a mental health professional for psychological treatment, and a sports dietitian $[3,6]$.

The individual's calorie needs should be increased to $20-30 \%$ above baseline requirements producing a gradual increase in body weight over time [3]. A target calorie value for EA of $45 \mathrm{kcal} / \mathrm{kg} \mathrm{FFM} /$ day for females and $40 \mathrm{kcal} / \mathrm{kg} \mathrm{FFM/day} \mathrm{for} \mathrm{males} \mathrm{must} \mathrm{be} \mathrm{achieved} \mathrm{through}$ dietary counseling with a sports dietitian or other health professional $[38,39]$. EA is calculated as energy intake (kcal) - exercise energy expenditure (kcal) / fat-free mass $(\mathrm{kg})$. A registered dietitian can assess energy intake through three-day dietary logs or an online dietary recording tool. Exercise energy expenditure can be estimated using exercise logs matched with heart rate monitors or using the Compendium of Physical Activity. Other target interventions include modifying unhealthy behaviors such as dietary restriction and/ or overtraining while addressing biomechanical factors that may contribute to bone stress [40].

While more educational resources are available today (and helpful websites are listed in Table 1.), awareness needs to continue to increase via popular media outlets, educational materials, and word of mouth. In addition, discussions regarding performance, health, and weight are necessary to counter the idea that "thinner is better" and that weight is an essential factor in performance. Programs such as Athletes Targeting Healthy Exercise and Nutrition Alternatives (ATHENA), a harm reduction/health promotion program for high school athletes, will be critical moving forward to help educate young athletes in the reduction of diet pill use and unhealthy eating behaviors [41].

\begin{tabular}{|l|}
\hline$\underline{\text { https://femaleathletetriad.org }}$ \\
\hline$\underline{\text { https://www.thinkeatplay.org/traid-talk/ }}$ \\
\hline$\underline{\text { https://www.sportsnutritionsociety.org/find-a-nutritionist.html }}$ \\
\hline$\underline{\text { https://kidshealth.org/en/teens/triad.html }}$ \\
\hline $\begin{array}{l}\text { https://orthoinfo.aaos.org/en/diseases--conditions/female- } \\
\text { athlete-triad-problems-caused-by-extreme-exercise-and-dieting/ }\end{array}$ \\
\hline$\underline{\text { https://www.ncaa.org/sites/default/files/Female\%20Athlete\%20 }}$ \\
\hline$\underline{\text { Triad.pdf }}$ \\
\hline \\
\hline
\end{tabular}

\section{Conclusion}

All exercising males and females, including competitive athletes, are at risk for developing the Triad, an interrelated spectrum of disorders that can negatively impact acute and long-term health. Decreased EA can result from single or a combination of factors including an underlying eating disorder, intentional dietary restriction to reduce body weight or improve body composition, or unintentional failure to adjust EI either due to lack of knowledge of requirements or exercise-induced appetite suppression [6]. Certain athletes, such as those participating in aesthetic sports, endurance sports, and sports with weight-class requirements as being particularly susceptible to 
prolonged periods of low EA. While a clinical threshold of $<30$ $\mathrm{kcal} / \mathrm{kg}$ FFM/day has been shown to cause negative metabolic and endocrine changes [12,13], research has demonstrated some women experience subclinical and clinical menstrual disturbances above this level $[14,15]$.

The Female Athlete Triad Coalition Consensus Statement has published tools to promote the early identification and treatment of athletes at increased risk of negative health outcomes [3]. Another tool for assessing EA specifically includes the LEAF-Q, which can help provide early identification of low energy intake, which is ultimately the first factor in producing Triad-related clinical manifestations.

Considering the critical stage of bone accumulation by males and females, it is important to properly diagnose the presence of one or more components of the Triad, as lack of prompt treatment can severely impact the ability to increase and maintain bone mass. In addition, the incorporation of standards and a protocol for athletes who are seeking unrealistic body weight and body composition values and criteria for an athlete in this condition to not be allowed to participate [42]. The multidisciplinary team, including an independent or team physician, parents, coaches, registered dietitian, certified athletic trainer, the mental health provider, and physical therapist must work together to develop this protocol which may allow for both prevention and early detection of disordered eating and eating disorders [3]. The PPE is a key time for allowing key members of the medical team to properly identify the presence of one or more of the Triad components $[4,43]$. Therefore, adequate screening procedures, including Triad-related screening questionsshould be included within the PPE for both high-school and collegiate athletes [3]. With the proper identification, screening, and diagnostic procedures, as well as educational effort focused on the Triad, clinicians, educators, and athletes, can help prevent and treat acute and long-term consequences of this condition in exercising males and females.

Conflicts of interest/Competing interests: I have no known conflicts of interest to disclose.

\section{References}

1. Kirkcaldy, B. D., Shephard, R. J., \& Siefen, R. G. (2002). The relationship between physical activity and self-image and problem behavior among adolescents. Social Psychiatry and Psychiatric Epidemiology, 37(11), 544-550. https://doi: 10.1007/s00127-002-0554-7

2. Otis, C. L., Drinkwater, B., Johnson, M., Loucks, A., \& Wilmore, J. (1997). ACSM position stand: The female athlete triad. Medicine \&Amp Science in Sports \&Amp exercise, 29(5), i-ix. https://doi: 10.1097/00005768-199705000-00037

3. De Souza, M. J. D., Nattiv, A., Joy, E., Misra, M., Williams, N. I., Mallinson, R. J. Gibbs, J.C., Olmsted, M., Goolsby \& Matheson, G. (2014). 2014 Female Athlete Triad Coalition Consensus Statement on Treatment and Return to Play of the Female Athlete Triad. British Journal of Sports Medicine, 48(4), 289-289. https://doi: 10.1136/bjsports-2013-093218

4. Thein-Nissenbaum, J. M., Rauh, M. J., Carr, K. E., Loud, K. J., \& Mcguine, T. A. (2011). Associations between disordered eating, menstrual dysfunction, and musculoskeletal injury among high school athletes. Journal of Orthopaedic \& Sports Physical Therapy, 41(2), 60-69. https://doi:10.2519/jospt.2011.3312

5. Martinsen, M., \& Sundgot-Borgen, J. (2013). Higher prevalence of eating disorders among adolescent elite athletes than controls. Medicine \& Science in Sports \& Exercise, 45(6), 1188-1197. https://doi: 10.1249/mss.0b013e318281a939
6. Nattiv A., Loucks A.B., Manore, M.M., Sanborn, F., SundgotBorgen, J. \& Warren, M.P. (2007). American College of Sports Medicine position stand: The female athlete triad. Medicine \& Science in Sports \& Exercise. 39(10), 1867-1882. https://doi: 10.1249/mss.0b013e318149f111

7. De Souza, M., Koltun, K., Strock, N., \& Williams, N. (2019). Rethinking the concept of an energy availability threshold and its role in the Female Athlete Triad. Current Opinion In Physiology, 10, 35-42. https://doi.org/10.1016/j.cophys.2019.04.001

8. Melin, A., Heikura, I., Tenforde, A., \& Mountjoy, M. (2019). Energy Availability in Athletics: Health, Performance, and Physique. International Journal Of Sport Nutrition And Exercise Metabolism, 29(2), 152-164. https://doi.org/10.1123/ ijsnem.2018-0201

9. Logue, D., Madigan, S. M., Delahunt, E., Heinen, M., Donnell, S.-J. M., \& Corish, C. A. (2017). Low energy availability in athletes: A review of prevalence, dietary patterns, physiological health, and sports performance. Sports Medicine, 48(1), 73-96. https://doi: 10.1007/s40279-017-0790-3

10. Loucks, A.B. (2014). Energy balance and energy availability. In R.J. Maughan (Ed.), The Encyclopedia of Sports Medicine: An IOC medical commission publication (1st ed., pp. 72-87). New York, NY; John Wiley \& Sons https://doi. org/10.1002/9781118692318.ch5

11. Thomas, D. T., Erdman, K. A., \& Burke, L. M. (2016). Position of the academy of nutrition and dietetics, dietitians of Canada, and the American College of Sports Medicine: Nutrition and athletic performance. Journal of the Academy of Nutrition and Dietetics, 116(3), 501-528. https://doi: 10.1016/j. jand.2015.12.006

12. Ihle, R., \& Loucks, A. B. (2004). Dose-response relationships between energy availability and bone turnover in young exercising women. Journal of Bone and Mineral Research, 19(8), 1231-1240. https://doi: 10.1359/jbmr.040410

13. Loucks, A. B., \& Thuma, J. R. (2003). Luteinizing hormone pulsatility is disrupted at a threshold of energy availability in regularly menstruating women. The Journal of Clinical Endocrinology \& Metabolism, 88(1), 297-311. https://doi: 10.1210/jc.2002-020369

14. Williams, N. I., Leidy, H. J., Hill, B. R., Lieberman, J. L., Legro, R. S., \& De Souza, M. J. (2015). Magnitude of daily energy deficit predicts frequency but not severity of menstrual disturbances associated with exercise and caloric restriction. American Journal of Physiology-Endocrinology and Metabolism, 308(1). https://doi:10.1152/ajpendo.00386.2013

15. Lieberman, J. L., DE Souza, M. J., Wagstaff, D. A., \& Williams, N. I. (2018). Menstrual disruption with exercise is not linked to an energy availability threshold. Medicine and Science in Sports and Exercise, 50(3), 551-561. https://doi.org/10.1249/ MSS.0000000000001451

16. Koehler, K., Hoerner, N., Gibbs, J., Zinner, C., Braun, H., De Souza, M., \& Schaenzer, W. (2016). Low energy availability in exercising men is associated with reduced leptin and insulin but not with changes in other metabolic hormones. Journal Of Sports Sciences, 34(20), 1921-1929. https://doi.org/10.1080/02 640414.2016.1142109

17. Burke, L. M., Lundy, B., Fahrenholtz, I. L., \& Melin, A. K. (2018). Pitfalls of conducting and interpreting estimates of energy availability in free-living athletes. International Journal of Sports Nutrition and Exercise Metabolism, 28(4), 350-363. https://doi: 10.1123/ijsnem.2018-0142

18. Holtzman, B., \& Ackerman, K. E. (2019). Measurement, determinants, and implications of energy intake in athletes. Nutrients, 11(3), 665. https://doi.org/10.3390/nu11030665 
19. Capling, L., Beck, K., Gifford, J., Slater, G., Flood, V., \& O'Connor, H. (2017). Validity of dietary assessment in athletes: A systematic review. Nutrients, 9(12), 1313. https://doi: 10.3390/nu9121313

20. Meczekalski, B., Podfigurna-Stopa, A., \& Genazzani, A. R. (2010). Hypoestrogenism in young women and its influence on bone mass density. Gynecological Endocrinology, 26(9), 652657. https://doi: 10.3109/09513590.2010.486452

21. Tenforde, A., Barrack, M., Nattiv, A., \& Fredericson, M. (2015). Parallels with the female athlete triad in male athletes. Sports Medicine, 46(2), 171-182. https://doi.org/10.1007/s40279-0150411-y

22. Papageorgiou, M., Dolan, E., Elliott-Sale, K., \& Sale, C. (2017). Reduced energy availability: implications for bone health in physically active populations. European Journal of Nutrition, 57(3), 847-859. https://doi.org/10.1007/s00394-017-1498-8

23. Friedl, K., Moore, R., Hoyt, R., Marchitelli, L., Martinez-Lopez, L., \& Askew, E. (2000). Endocrine markers of semistarvation in healthy lean men in a multistressor environment. Journal Of Applied Physiology, 88(5), 1820-1830. https://doi.org/10.1152/ jappl.2000.88.5.1820

24. Geesmann, B., Gibbs, J., Mester, J., \& Koehler, K. (2017). Association between energy balance and metabolic hormone suppression during ultraendurance exercise. International Journal Of Sports Physiology And Performance, 12(7), 984989. https://doi.org/10.1123/ijspp.2016-0061

25. Kupchak, B., Kraemer, W., Hoffman, M., Phinney, S., \& Volek, J. (2014). The impact of an ultramarathon on hormonal and biochemical parameters in men. Wilderness \& Environmental Medicine, 25(3), 278-288. https://doi.org/10.1016/j. wem.2014.03.013

26. Wheeler, G., Singh, M., Pierce, W., Epling, W., \& Cumming, D. (1991). Endurance Training Decreases Serum Testosterone Levels in Men without Change in Luteinizing Hormone Pulsatile Release. The Journal Of Clinical Endocrinology \& Metabolism, 72(2), 422-425. https://doi.org/10.1210/jcem-72-2-422

27. Gannon, J., \& Walsh, T. (2016). Testosterone and Sexual Function. Urologic Clinics Of North America, 43(2), 217-222. https://doi.org/10.1016/j.ucl.2016.01.008

28. Rauh, M. J., Barrack, M., \& Nichols, J. F. (2014). Associations between the female athlete triad and injury among high school runners. International Journal of Sports Physical Therapy, 9(7), 948-58.

29. Li, D., Hitchcock, C. L., Barr, S. I., Yu, T., \& Prior, J. C. (2013). Negative spinal bone mineral density changes and subclinical ovulatory disturbances-Prospective data in healthy premenopausal women with regular menstrual cycles. Epidemiologic Reviews, 36(1), 137-147. https://doi:10.1093/ epirev/mxt012

30. Dolan, E., Crabtree, N., McGoldrick, A., Ashley, D., McCaffrey, N., \& Warrington, G. (2011). Weight regulation and bone mass: a comparison between professional jockeys, elite amateur boxers, and age, gender, and BMI matched controls. Journal of Bone and Mineral Metabolism, 30(2), 164-170. https://doi. org/10.1007/s00774-011-0297-1

31. Dias Quiterio, A., Carnero, E., Baptista, F., \& Sardinha, L. (2011). Skeletal Mass in Adolescent Male Athletes and Nonathletes: Relationships with High-Impact Sports. Journal of Strength and Conditioning Research, 25(12), 3439-3447. https://doi.org/10.1519/jsc.0b013e318216003b
32. Kraus, E., Nattiv, A., Tenforde, A., Kim, B., Kussman, A., \& Fredericson, M. (2015). Patterns of Bone Stress Injuries in Division I Collegiate Distance Runners: A Retrospective Cohort Study. PM\&R, 7, S89-S89. https://doi.org/10.1016/j. pmrj.2015.06.033

33. Manore, M. M., Kam, L. C., \& Loucks, A. B. (2007). The female athlete triad: Components, nutrition issues, and health consequences. Journal of Sports Sciences, 25(sup1). https://doi: 10.1080/02640410701607320

34. Melin, A., Tornberg, Å. B., Skouby, S., Møller, S. S., SundgotBorgen, J., Faber, J., Sidelmann, J.J. \& Sjödin, A. (2014). Energy availability and the female athlete triad in elite endurance athletes. Scandinavian Journal of Medicine \& Science in Sports, 25(5), 610-622. https://doi: 10.1111/sms.12261

35. The Female and Male Athlete Triad Coalition. (2020, February 11). https://www.femaleandmaleathletetriad.org/

36. Michopoulos, V., Mancini, F., Loucks, T. L., \& Berga, S. L. (2013). Neuroendocrine recovery initiated by cognitive behavioral therapy in women with functional hypothalamic amenorrhea: A randomized, controlled trial. Fertility and Sterility, 99(7), 20842091. https://doi: 10.1016/j.fertnstert.2013.02.036

37. Busanich, R., Mcgannon, K. R., \& Schinke, R. J. (2014). Comparing elite male and female distance runners' experiences of disordered eating through narrative analysis. Psychology of Sport and Exercise, 15(6), 705-712. https://doi:10.1016/j. psychsport.2013.10.002

38. Southmayd, E. A., Hellmers, A. C., \& Souza, M. J. D. (2017). Food versus pharmacy: Assessment of nutritional and pharmacological strategies to improve bone health in energydeficient exercising women. Current Osteoporosis Reports, 15(5), 459-472. https://doi: 10.1007/s11914-017-0393-9

39. Mallinson, R. J., Williams, N. I., Olmsted, M. P., Scheid, J. L., Riddle, E. S., \& Souza, M. D. (2013). A case report of recovery of menstrual function following a nutritional intervention in two exercising women with amenorrhea of varying duration. Journal of the International Society of Sports Nutrition, 10(1), 34. https://doi: 10.1186/1550-2783-10-34

40. Stickler, L., Hoogenboom, B. J., \& Smith, L. (2015). The female athlete triad-What every physical therapist should know. International Journal of Sports Physical Therapy, 10(4), 563571. https://ifspt.org/education/journals/

41. Elliot, D. L., Goldberg, L., Moe, E. L., Defrancesco, C. A., Durham, M. B., McGinnis, W., \& Lockwood, C. (2008). Longterm Outcomes of the ATHENA (Athletes Targeting Healthy Exercise \& Nutrition Alternatives) Program for Female High School Athletes. Journal of Alcohol and Drug Education, 52(2), 73-92. https://journals.sagepub.com/home/drea

42. Sundgot-Borgen, J., Meyer, N. L., Lohman, T. G., Ackland, T. R., Maughan, R. J., Stewart, A. D., \& Müller, W. (2013). How to minimize the health risks to athletes who compete in weight-sensitive sports review and position statement on behalf of the ad hoc research working group on body composition, health and performance, under the auspices of the IOC medical commission. British Journal of Sports Medicine, 47(16), 10121022. https://doi: 10.1136/bjsports-2013-092966

43. Temme, K. E., \& Hoch, A. Z. (2013). Recognition and rehabilitation of the female athlete triad/tetrad. Current Sports Medicine Reports, 12(3), 190-199. https://doi: 10.1249/ jsr.0b013e318296190b 